\title{
Application of tailored testing to achievement measurement
}

\author{
RICHARD A. ENGLISH, MARK D. RECKASE, and WAYNE M. PATIENCE \\ University of Missouri, Columbia, Missouri 65201
}

\begin{abstract}
This paper reports the findings of a study comparing differences on the levels of achievement, differences in time needed to take a test, and differences in attitudes between subjects taking a traditional paper-pencil test and those taking a computerized tailored test. A maximum likelihood tailored testing procedure based on the Rasch simple logistic model was used for the study. Subjects were 106 upper level undergraduate students enrolled in a measurement and evaluation course. Analyses included descriptive statistics on all variables for all conditions, intercorrelations of all variables within each treatment condition, and analyses of variance. Results indicate no differences in the level of achievement between subjects taking paper-pencil tests and those taking the tailored tests. A time savings of $75 \%$ was found using the tailored testing model. Subjects indicated that tailored tests were less stressful.
\end{abstract}

For several years now, computer administration of tests has been used by developers of computer-assisted instruction procedures (Atkinson, 1968; Suppes, 1966). However, the procedures controlling the administration have seldom reached the level of development of the current models, which are known by a variety of labels including adaptive testing (Weiss \& Betz, 1973), computer-assisted testing (Crick, Note 1), responsecontingent testing (Wood, Note 2), sequential item testing (Krathwohl \& Huyser, 1956), and tailored testing (Lord, 1970). A limited amount of research has been done to evaluate those new procedures for achievement testing.

This paper reports on an empirical test of computerized tailored testing as it relates to achievement testing. Tailored testing is a system designed to administer tests or, more specifically, individual items, tailored to an individual's ability. The system utilizes the computational and storage capabilities of the computer to identify, select, and administer to each individual the items best able to measure the ability of the individual. Items that tend to be too easy or too difficult for an individual are avoided.

Hansen (1969), using a computer-based branched testing model, found a significant improvement in internal consistency reliability for computer presentation $(r=.80)$ when compared to a conventional classroom achievement $(r=.43)$. Hansen further reported a significant relationship $(r=.76)$ between computerbased test results and college aptitude scores.

Ferguson (Note 3) applied sequential procedures to criterion-referenced measurement using computer administration of achievement items. Subjects were 75 students in Grades 1 to 6 . Results on the computer test were compared with paper-pencil test scores. He found a $60 \%$ time savings in the computerized test administration. Ferguson also found higher test-retest reliabilities using the computerized sequential procedure when compared with reliabilities found using the paperpencil approach.

Hansen (1975) noted that most findings comparing conventional ability testing to computer-based testing are based on theoretical or simulation studies, and are not consistent with the limited empirical observations.

\section{PROBLEM}

The purpose of this study is to attempt to answer the following questions:

1. Is there any difference in levels of achievement of students taking paper-pencil tests and those using tailored testing procedures in an upper level tests and measurement course?

2 . Is there any difference in the amount of time needed to take a paper-pencil test and to take tests on a computer-terminal in the same course?

3 . Is there any difference in the attitude of students taking paper-pencil tests and those using tailored testing procedures in an upper level tests and measurement course?

\section{METHOD}

The subjects for this study were upper level undergraduate students enrolled in a course entitled "Introduction to Educational Measurement and Evaluation." The course is required for education majors in the College of Education on the University of Missouri-Columbia campus. It is an 8-week course, meeting for $50 \mathrm{~min}$ a day, 4 days a week.

Prior to the beginning of the course, students were randomly assigned to four experimental groups. During the first class period, all students received a course outline and objectives. Students attended the same lectures through the 8 weeks, and each experimental group took three exams. Following Exams 1 and 2, feedback sessions for all students were made available covering any missed material.

Experimental Group 1 (PP) took the traditional paperpencil test on Exams 1 and 2 (50 items). Experimental Group 2 (PT) took the paper-pencil test on Exam 1 (50 items) 
and a tailored test on Exam 2. Group 3 (TP) took a computerterminal test on the first exam and a paper-pencil test on the second exam (50 items). Experimental Group 4 (TT) took both exams using the computer-terminal tests. All the computerized testing used the simple logistic tailored testing procedures described in Reckase (1974). A 20-item limit was imposed for the tailored test to keep the testing time to about $30 \mathrm{~min}$.

There were 38 subjects in the PP group, 18 in the PT group, 29 in the TP group, and 21 subjects in the TT group, for a sample total of 106. All subjects took the same final exam using a paper-pencil format.

The computer was an IBM 370/168 with timesharing capability and a Beehive Mini-Bee II cathode ray terminal. The items were calibrated using the Rasch simple logistic model (Rasch, 1960). This procedure relates the probability of a correct response to the ability of the person to the easiness of the item. Only a simple parameter, item easiness, is used to describe the items.

\section{Analyses}

The following data were collected on each of the experimental groups. On Exams 1 and 2, standard scores with a mean of 50 and a standard deviation (SD) of 10 were recorded for those taking the paper-pencil test, and $\log$ ability scores were recorded for those taking the test on the computer terminal. Standard scores were collected for all conditions on Exam 3.

Exam 3 was broken down into three parts. Part 1 (T3P1) consisted of 50 items which tested the final one-third of the course. Part 2 (T3P2) of the exam (25 items) covered the first one-third of the course, and Part 3 (T3P3, 25 items) covered the middle third. The total score on the exam (sum of the three parts) was also recorded (T3).

Grade-point averages (GPA), the Missouri-Placement Test scores, Missouri College Entrance Test (MCET) scores, Scat verbal, quantitative, and total scores, and high school rank were obtained on students where the data were available. The number of items administered on Exams 1 and 2 to subjects using the computer terminal (tailored testing) conditons were recorded. Finally, a four-item attitude questionnaire was given to determine student attitudes on the tailored testing procedures. The attitude statements were:

(A1) Compared to multiple-choice tests, the tailored test has (a) more time pressure, (b) less time pressure, (c) about equal time pressure.

(A2) Compared to traditional multiple-choice tests, the tailored test is (a) easier, (b) harder, (c) about as difficult.

(A3) Compared to the traditional multiple-choice test, (a) I would rather take the tailored test, (b) I would rather take the traditional test, (c) I prefer both equally well.

(A4) Taking the test on the computer terminal makes me (a) more anxious than a traditional test, (b) less anxious than a traditional test, (c) about equally as anxious as the traditional test.

The analyses performed on all the dependent variables were as follows: Means, SDs, skewness, and kurtosis values were determined on all variables for all conditions (see Table 1). Further analyses consisted of the intercorrelation of all variables within each of the treatment conditions (see Tables 2 and 3 ).

Analyses of variance were run on the subscores of the third test and the total score (T3P1, T3P2, T3P3, and T3T).

\section{RESULTS}

Table 1 presents the means, SDs, skewness, and kurtosis values for the four experimental groups. Based on the skewness and kurtosis values, the distributions for tailored testing are not significantly different from the normal distributions. However, in two cases, the testscore distributions for the traditional paper-pencil tests did deviate from the normal distribution $(\mathrm{p}<.05)$. Because of the small sample size, a significance of kurtosis could not be computed. However, T1 for

Table 1

Summary of Means, Standard Deviations, Skewness, and Kurtosis Over the Dependent Variables for the Experimental Groups

\begin{tabular}{|c|c|c|c|c|c|c|c|c|c|c|c|c|c|c|c|c|}
\hline \multirow[b]{2}{*}{ Variables } & \multicolumn{4}{|c|}{ Experimental Group PP } & \multicolumn{4}{|c|}{ Experimental Group PT } & \multicolumn{4}{|c|}{ Experimental Group TP } & \multicolumn{4}{|c|}{ Experimental Group TT } \\
\hline & Mean & SD & Skew & Kurt & Mean & SD & Skew & Kurt & Mean & SD & Skew & Kurt & Mean & SD & Skew & Kurt \\
\hline T1 & 50.68 & 2.67 & $-1.38 *$ & 2.59 & 53.33 & 4.23 & .45 & -.86 & 49.00 & 11.00 & -.41 & 1.25 & 51.24 & 8.47 & .64 & -.67 \\
\hline L1 & & & & & & & & & 2.34 & 1.1 & -.34 & 1.20 & 2.60 & .87 & .64 & -.64 \\
\hline T2 & 49.16 & 10.11 & -.71 & -.18 & 52.00 & 9.53 & -.67 & -.27 & 50.48 & 10.43 & -.61 & -.54 & 49.43 & 10.55 & -.35 & .24 \\
\hline L2 & & & & & 2.47 & .71 & -.70 & -.23 & & & & & 2.21 &.$\quad 80$ & -.13 & .02 \\
\hline T3T & 50.42 & 9.98 & .14 & -.56 & 51.83 & 8.45 & .02 & -.67 & 49.24 & 11.04 & -.15 & -.78 & 50.24 & 9.65 & -.28 & -.42 \\
\hline T 3P 1 & 48.47 & 10.88 & .10 & -.59 & 52.44 & 6.48 & $-1.34^{*}$ & ${ }^{k} \quad 1.32$ & 50.55 & 9.55 & -.32 & -.67 & 51.57 & 11.07 & -.65 & -.43 \\
\hline T3P2 & 52.00 & 9.79 & -.23 & -.82 & 49.33 & 9.20 & -.01 & -.38 & 46.55 & 11.76 & -.29 & -.37 & 52.57 & 6.38 & -.04 & -1.13 \\
\hline T3P3 & 51.13 & 7.63 & .07 & -.48 & 52.00 & 11.05 & -.44 & -.53 & 50.90 & 11.19 & .07 & -.80 & 45.95 & 10.31 & -.55 & .47 \\
\hline GPA & 2.92 & .45 & .73 & -.29 & 2.97 & .50 & .66 & .11 & 3.11 & .45 & .05 & -.31 & 3.15 & .39 & -.27 & -.72 \\
\hline TOT & 200.95 & 34.46 & -.12 & -.38 & 209.00 & 22.89 & .25 & -.80 & 197.97 & 38.30 & -.54 & -.31 & 201.14 & 29.14 & .08 & -.93 \\
\hline MMPT & 17.12 & 7.36 & .32 & -.85 & 22.50 & 5.96 & .47 & -.91 & 21.06 & 7.49 & -.06 & -1.01 & 22.20 & 9.58 & -.41 & -1.42 \\
\hline MCET & 62.94 & 12.21 & -.10 & -.51 & 64.67 & 4.23 & .85 & -.43 & 60.83 & 13.98 & -.67 & -.02 & 68.10 & 11.69 & -.19 & -1.09 \\
\hline S VERB & 27.41 & 6.84 & 1.28 & 2.18 & 31.50 & 3.02 & -.96 & .10 & 27.83 & 8.41 & .03 & -.76 & 31.20 & 7.19 & -.65 & -.61 \\
\hline S QUANT & 25.47 & 8.70 & .67 & -.67 & 31.50 & 12.55 & .38 & -1.26 & 30.17 & 7.06 & -.34 & -.91 & 29.20 & 10.24 & -.39 & -1.30 \\
\hline S TOT & 52.88 & 13.87 & 1.09 & .91 & 63.00 & 14.64 & .07 & -1.33 & 58.00 & 14.01 & -.16 & -1.30 & 60.40 & 16.73 & -.64 & -1.06 \\
\hline HSR & 79.12 & 15.93 & -.70 & -.26 & 87.00 & 8.79 & .36 & -1.42 & 87.29 & 13.11 & -1.76 & 2.73 & 85.90 & 17.04 & -1.05 & -.44 \\
\hline NI1 & & & & & & & & & 11.14 & 4.58 & .82 & -.42 & 10.68 & 3.80 & .99 & .38 \\
\hline NI2 & & & & & 9.50 & 4.35 & 1.76 & 1.98 & & & & & 12.35 & 5.00 & .23 & -1.30 \\
\hline$A 1$ & & & & & 2.77 & .60 & -2.63 & 4.13 & 2.50 & .71 & -1.03 & -.23 & 3.00 & 0.00 & 0.00 & 0.0 \\
\hline A2 & & & & & 1.92 & .67 & .08 & -.58 & 1.94 & .80 & .10 & -1.35 & 2.00 & .87 & 0.0 & -1.50 \\
\hline A3 & & & & & 2.08 & .95 & -.15 & -1.79 & 1.72 & .90 & .57 & -1.44 & 2.40 & .97 & -.87 & -1.24 \\
\hline \multirow[t]{2}{*}{ A4 } & & & & & 1.01 & .65 & .50 & -.65 & 1.61 & .70 & .66 & -.67 & 2.00 & .67 & 0.00 & -.50 \\
\hline & \multicolumn{4}{|c|}{$\mathrm{n}=38$} & \multicolumn{4}{|c|}{$\mathrm{n}=18$} & \multicolumn{4}{|c|}{$\mathrm{n}=29$} & \multicolumn{4}{|c|}{$n=21$} \\
\hline
\end{tabular}


Table 2

Correlation Coefficients Between Test 1 and 2 Scores for Experimental Groups and Parts 1, 2, and 3 on Final Exam and Dependent Variables

\begin{tabular}{llccccccc}
\hline & \multicolumn{6}{c}{ Experimental Groups } \\
Variables & T1 & T2 & T1 & T2 & T1 & T2 & T1 & T2 \\
\hline T3P1 & $.77 \dagger$ & $.67 \dagger$ & .28 & .35 & $.54 \dagger$ & $.47 \dagger$ & .05 & $.58 \dagger$ \\
T3P2 & $.41 \dagger$ & $.52 \dagger$ & .25 & -.02 & $.36^{*}$ & $.48 \dagger$ & .11 & .34 \\
T3P3 & $.50 \dagger$ & $.40 \dagger$ & .15 & .25 & $.51 \dagger$ & $.67 \dagger$ & .03 & .37 \\
GPA & $.54 \dagger$ & $.40^{*}$ & -.10 & $.90 \dagger$ & $.57 \dagger$ & $.75 \dagger$ & .03 & $.47^{*}$ \\
MMPT & .27 & $.45^{*}$ & .27 & -.71 & .00 & $.42^{*}$ & .45 & $.65^{*}$ \\
MCET & .17 & .06 & .72 & $-.75^{*}$ & .34 & $.61 \dagger$ & .54 & .57 \\
S VERB & .30 & .19 & -.27 & $-.77^{*}$ & .35 & .21 & $.55^{*}$ & $.53^{*}$ \\
S QUANT & $.42^{*}$ & $.71 \dagger$ & .17 & -.71 & .06 & $.43^{*}$ & .54 & $.60^{*}$ \\
S TOT & $.41^{*}$ & $.54 *$ & .09 & $-.76^{*}$ & .24 & .34 & $.57^{*}$ & $.60^{*}$ \\
HSR & .12 & .38 & .54 & .50 & .34 & $.56 \dagger$ & .39 & .51 \\
& $\mathrm{n}=38$ & $\mathrm{n}=18$ & $\mathrm{n}=29$ & $\mathrm{n}=21$ \\
\hline
\end{tabular}

Group PP appears to be larger than the expected values, indicating the scores tend to concentrate in a small area.

The distribution of the number of items was significantly positively skewed in two cases. For the PT group, the number of items administered (NI2) had a skewness value of 1.76 and mean value of 9.5 points; for the TT group, the number of items administered (NI1) had a skewness of .99 and a mean value of 10.7 points. This means that the scores tend to concentrate at the lower end, indicating a large number of subjects required only a few items.

Table 2 gives the values of the correlations between the dependent variables for the four experimental groups. Twelve of the 14 coefficients comparing the PP and TT groups on the dependent variables are higher for the TT group, although some are not significantly different. This indicates higher criterion-related validity for those taking the tailored test than for those taking the paper-pencil test. Six of six correlations with final exam scores are higher for the paper-pencil group than for the tailored-test group. This perhaps indicates a lack of transfer of testing behaviors. The PT and TP groups have not been analyzed because of the interaction effects in the two-way analysis of variance. The interaction may have had an influence on the negative correlations in the two groups.

Only three correlations were significant in the attitude data (see Table 3). The correlation coefficient (-.52) for Group TP on the second test with Statement A1 indicates that people who did poorly on the paper-pencil test felt more time pressure on the tailored testing procedure.

The correlations for the TP group between the first test and Statements $A 2$ and $A 3$ indicate that people would rather take the tailored test than the paperpencil test.

A summary of the responses on the attitude statements of the experimental groups combined found
$78 \%$ of the subjects experiencing about equal time pressure when comparing multiple-choice tests and tailored tests. Approximately $44 \%$ of the subjects indicated that tailored tests were harder than the traditional tests, with approximately $30 \%$ of the subjects finding the tailored tests easier. Approximately $44 \%$ of the subjects preferred taking the tailored test, while 44\% preferred the tailored test and multiple-choice tests equally well. Approximately $47 \%$ of the subjects reported experiencing less anxiety while taking the test on the computer terminal; approximately $42 \%$ experienced more anxiety using the computer terminal.

Analyses of variance were run on the subscores and the total score of the third exam. No significant main effects were found in retention of material between subjects using the paper-pencil procedure and the computer-terminal procedure. A significant two-way interaction was found between the first and second testing procedures and T3P2 scores $[F(1,102)=4.85$, $\mathrm{p}<.05]$. The subjects who had the paper-pencil test first and the tailored test second (PT group) and those taking the tailored test first and the paper-pencil second (TP group) did significantly poorer than either the PP or TT groups. No other statistically significant differences were found.

\section{DISCUSSION}

The results of this study indicate that there essentially are no differences on the levels of achievement between students using the tailored testing model and those using the traditional model. However, the two-way interaction effects indicate an apparent interference effect when a student went from one test to a different procedure on the next test. To obtain a higher level of retention, the same procedure should be used throughout the learning experience.

A very significant finding of the study had to do with the number of items administered to the tailored testing groups compared to the multiple-choice groups. The mean number of items taken on the terminal by the experimental groups were, on the average, 9.5 and 10.8 . Since the paper-pencil tests were 50 items long, results indicate an approximate $75 \%$ reduction in the number of

Table 3

Correlation Coefficients Between Attitude Statements and Scores on Tests 1 and 2 for Experimental Groups

\begin{tabular}{lrrrrrr}
\hline $\begin{array}{l}\text { Attitude } \\
\text { State- } \\
\text { ments }\end{array}$ & $\mathrm{T} 1$ & $\mathrm{~T} 2$ & $\mathrm{~T} 1$ & $\mathrm{~T} 2$ & $\mathrm{~T} 1$ & $\mathrm{~T} 2$ \\
\hline $\mathrm{A} 1$ & -.26 & -.28 & -.31 & $-.52^{*}$ & $\dagger$ & $\dagger$ \\
A2 & -.46 & -.26 & $.45^{*}$ & -.35 & .48 & .37 \\
A3 & -.06 & .10 & $.72 * *$ & .13 & .50 & .08 \\
A4 & -.06 & .36 & .06 & -.38 & .47 & .19 \\
& \multicolumn{2}{c}{$\mathrm{n}=13$} & & $\mathrm{n}=18$ & $\mathrm{n}=10$ \\
\hline
\end{tabular}

${ }^{*} p<.05 \quad{ }^{* *} p<.01 \quad$ tSample size too small 
items used to test the students' achievement levels, and approximately a $50 \%$ savings in time.

The overall results of the attitude survey show that the subjects who used tailored testing felt less time pressure, thought the different tests about equal in difficulty, preferred the two tests equally, and found no differences between the two models in causing anxiety.

\section{REFERENCE NOTES}

1. Crick, J. E. A critical review of computer-assisted testing. Unpublished qualifying paper, University of Massachusetts, 1972.

2. Wood, R. Fully adaptive sequential testing: A Bayesian procedure for efficient ability measurement. Unpublished manuscript. University of Chicago, 1972.

3. Ferguson, R. L. Computer assistance for individualizing measurement. Technical Report, University of Pittsburg. 1971.

\section{REFERENCES}

Atkinson, R. C. Computer-based instruction in initial reading. Proceedings of the 1967 Invitational Conference on Testing Problems. Princeton, N.J: Educational Testing Service, 1968.

HANSEN, D. N. An investigation of computer-based science testing. In R. C. Atkinson \& H. A. Wilson (Eds.), Computerassisted instruction: $A$ book of readings. New York: Academic Press, 1969.

Hansen, D. N., Johnson, B. F., Fagan, R. L., Tan, P., \& Dick, W. Computer-based adaptive testing models for the Air Force technical training environment: Phase $I$. Development of a computerized measurement system for Air Force technical training. JSAS Catalogue of Selected Documents in Psychology, 1975, 5, 1-86. (MS No. 882)

Krathwohl, D. R., \& Huyser, R. J. The sequential item test (SIT). American Psychologist, 1956, 11, 419.

LoRd, F. M. Some test theory for tailored testing. In W. H. Holtzman (Ed.), Computer-assisted instruction, testing, and guidance. New York: Harper \& Row, 1970.

Rasch, G. Probabilistic models for some intelligence and attainment tests. Copenhagen: Denmarks Paedogogishe Institute, 1960.

RECKASE, M. D. An interactive computer program for tailored testing based on the one-parameter logistic model. Behavior Research Methods \& Instrumentation, 1974, 6, 208-212.

Suppes, P. The uses of computers in education. Scientific American, 1966, 215, 206-221.

WEISS, D. J., \& BETz, N. E. Ability measurement: Conventional or adaptive? (Research Report 73-1). Minneapolis: University of Minnesota, 1973. (NTIS No. Ad 757788) 